\title{
Enhancing Diversity in STEMM
}

\author{
Mary Alice Haddad $^{1 *}$, Tyler Jenkins ${ }^{2}$, Bonnie Solivan ${ }^{3}$ and Alison Williams ${ }^{4}$ \\ ${ }^{1}$ John E. Andrus Professor of Government, Director of Faculty Career Development, Wesleyan University, Middletown, CT, \\ United States, ${ }^{2}$ Wesleyan University, Middletown, CT, United States, ${ }^{3}$ Academic Technologist, Wesleyan University, Middletown, \\ CT, United States, ${ }^{4}$ Vice President for Equity and Inclusion/Title IX Officer, Wesleyan University, Middletown, CT, United States
}

Professional and scientific societies can foster inclusive environments that can enhance the diversity of their respective fields and disciplines, but some associations are doing a better job than others. This paper reviewed more than a dozen professional associations and their efforts to support diversity as reported online in an effort to identify successful examples. It finds that resources generally fall into two categories: 1) Websites highlighting the accomplishments of specific individuals, which raise the profile of diverse practitioners in the field. 2) Membership associations that support under-represented communities within a particular field. This article will offer a review of the resources available and some recommendations for how professional associations can better enhance their support for diversity and inclusion in their fields.

Keywords: STEM-science technology engineering mathematics, diversity and inclusion, networks, professional associations, websites analysis

\section{OPEN ACCESS}

Edited by:

Veronica A. Segarra,

High Point University, United States

Reviewed by:

Brett Woods,

High Point University, United States

Dajoie Croslan Baker,

American Institute of Biological

Sciences, United States

${ }^{*}$ Correspondence:

Mary Alice Haddad

mahaddad@wesleyan.edu

Specialty section: This article was submitted to STEM Education, a section of the journal

Frontiers in Education

Received: 09 August 2021 Accepted: 27 September 2021 Published: 18 October 2021

Citation:

Haddad MA, Jenkins T, Solivan B and Williams A (2021) Enhancing Diversity in STEMM.

Front. Educ. 6:755758. doi: 10.3389/feduc.2021.755758

\section{INTRODUCTION}

STEMM (Science, Technology, Engineering, Mathematics, and Medicine) fields are notorious for their lack of diversity (Briggs, 2017; Jones et al., 2018; Botella et al., 2019), and professional associations are increasingly recognizing their responsibility to rectify this weakness in their fields. In the wake of the 2020 Black Lives Matter protests, every professional association we reviewed made some kind of statement related to supporting the movement, endorsing diversity, and/or taking responsibility for perpetuating racism in their fields. ${ }^{1}$ A year later, the authors reviewed what they report they are doing. How are STEMM professional associations supporting diversity in their fields?

The authors performed a comprehensive review of more than twenty professional association websites (Appendix for full list) across a range of STEMM fields. We found that, with a few exceptions, most of the diversity-promoting resources in the STEMM professions were being offered by identity-based associations that focused on particular underrepresented communities within STEMM. In our review, we were surprised to discover that it was harder to find these resources than we had expected, and there was no single place where all relevant resources were gathered. To address this difficulty, we created two such resources: Diverse Faculty Listings and Scholar Networks).

After a brief overview of what we found in our review of the professional associations' online resources, we will discuss the two types of resources that we found directed towards STEMM professionals: those facilitating finding underrepresented scholars in specific fields and those supporting networking among professionals with a particular identity. For each type of resource, we will offer a few examples intended to highlight the range of resources and making note of groups that are supporting diversity in their respective fields.

\footnotetext{
${ }^{1}$ To give just four examples: AAAS CEO statement in support of \#ShutDownSTEM, National Academies of Science statements,
} APS letter condemning racism, Royal Society of Chemistry statement. 


\section{OVERVIEW OF SCIENCE, TECHNOLOGY, ENGINEERING, MATHEMATICS, AND MEDICINE PROFESSIONAL ASSOCIATIONS' DIVERSITY EFFORTS}

The first step in enhancing diversity is to demonstrate that people from all backgrounds can enter the field. It is very difficult to enter a field if you cannot imagine yourself in that field, and it is difficult to imagine yourself in that field if you have never seen anyone who looks like you practicing that profession. There is now considerable research documenting the importance of offering diverse role models, so students, faculty, and professionals can see people who look like themselves being successful in the field (Drury et al., 2011; Yonas et al., 2020; Steinke et al., 2021).

Not surprisingly, there is a wide range of ideas about what constitutes diversity. In our search, we limited ourselves to looking for 1) visible images of people who looked different from one another, 2) highlighted accomplishments of people who are generally underrepresented in STEMM fields (i.e., black, Latinx, LGBTQ+, women, etc.,), 3) evidence of gender and racial diversity in leadership, 4) programs that improved access, visibility, and provided career-enhancing opportunities for professionals from underrepresented identities. We recognize that these are not allencompassing search criteria.

Four mainline associations stood out as positive examples of STEMM professional associations that appeared to have active and comprehensive efforts to enhance diversity in their fields. All four organizations had diverse images of professionals on their landing pages, and all listed extensive diversity initiatives. Their initiatives featured some combination of research contributions and profiles of professionals from diverse backgrounds, teaching resources designed to help with recruitment, explicit discussion of benchmarks related to progress on equity and inclusion initiatives, and other similar diversity-enhancing initiatives: American Association for the Advancement of Science, American Geophysical Union, American Society for Biochemistry and Molecular Biology, and the American Society for Cell Biology.

Finally, we examined the Board of Directors (or Board of Trustees) for each of the professional associations that we surveyed. Most associations had pictures of their current Board members listed on their websites, so it was possible to showcase the diversity (or lack thereof) among their leadership. Three professional associations we reviewed had multiple women and people of color among their top leadership: American Association for the Advancement of Science, American Chemical Society, and the American Medical Association. Two associations stood out because they had both diverse boards and they also had presidents who were people of color: American Society of Mechanical Engineers and the American Psychological Association.

In sum, some STEMM professional associations are making strong efforts to promote diversity in their fields. However, these efforts cannot reach everyone, and they are maldistributed across STEMM fields. It is not surprising, therefore, that groups of scholars and professionals from non-traditional backgrounds have formed identity-based organizations to support one another in their respective fields. It is these organizations, which are also professional associations, that are filling in the gaps left by the broader discipline-based professional associations. The resources supporting diverse professionals presented by these organizations generally fell into two categories: showcasing the talent of diverse professionals and connecting professionals from particular groups to one another in mutual-support networks.

\section{SHOWCASING DIVERSE SCHOLARS}

With the growing recognition of the importance of offering diverse role models in STEMM fields, several projects to highlight diversity in STEMM have sprung up outside professional associations. Diversify STEM Conferences offers a searchable of diverse speakers at STEM conferences as well as a mechanism for speakers to join their list and a pilot initiative for conference tracking. I Am A Scientist offers profiles of a diverse set of real-world scientists and educational materials to inspire students. The award-winning film Picture a Scientist, chronicles the journey of a new generation of women scientists and how they are working to make science more equitable and inclusive. \#llooklikeanengineer offers a repository of selfies posted by diverse engineers, showcasing the large variety of professionals in the field.

Three identity-based professional organizations were among the best ones that we found for showcasing the talent of their members. Their websites enabled visitors to find speakers to give talks, collaborators for projects, or other professional networking purposes. The photos, bios, social media handles, and professional website links were all publicly available, making it easy for members and non-members alike to see and connect with STEMM scholars in specific fields from specific under-represented groups.

The Society for Advancing Chicanos/Hispanics \& Native Americans in Science (SACNAS) is one of the oldest and most extensive groups that we found supporting underrepresented groups in STEMM. With more than 8,000 members in 118 national chapters, the organization has been active for almost 50 years. Its biography project includes numerous profiles of active professionals and graduate students and is searchable by discipline and ethnicity. In addition to publicizing the accomplishments of its members, the organization also offered a diverse set of professional support opportunities including annual conferences, webinars, leadership programs, and awards. It is also active in policy advocacy.

For reasons that were unclear to the authors, neuroscience as a field appears to be doing the best of all the STEMM disciplines at showcasing the contributions of diverse practitioners and facilitating access to those professionals. Women in Neuroscience has a keywordsearchable database of almost 2,000 professionals from around the world. Adding yourself to the database is free and easy. Black In Neuro also has a keyword searchable member directory that is full of talented (mostly young) professionals. In addition to the searchable member directory, the organization hosts an annual conference, networking socials, and themed workshops (e.g., salary negotiation, mentoring).

\section{CONNECTING DIVERSE SCHOLARS}

Most of the identity-based professional associations that we found were less focused on showcasing talent and were more 
concerned with fostering professional success for their members. These groups generally offer services and support for members ranging from annual conferences and regular newsletters to legal and mentoring support. There are many, many of these groups across all of the STEMM fields, supporting different configurations of identity-professional intersections. We will highlight just a few of them here to provide an idea of the range of organizations available. We have gathered all of the diversitysupporting professional organizations that we could find in this listing of scholar networks. ${ }^{2}$ Another good resource of organizations supporting underrepresented minorities in STEM is this list, maintained by Diversify STEM Conferences.

American Association of University Women (AAUW) is the oldest organization that we found supporting diversity in STEMM (and other) professions. Founded in 1881, AAUW has been active in supporting women's career advancement inside and outside of academia and has been particularly active in promoting national legislative agendas to support professional women. Its Strategic Plan 2.0 emphasizes equity and antiracism efforts and a focus on STEM. The organization is active in supporting women in STEM through its research, advocacy, and scholarships. Other well-established womensupporting organizations focusing on particular professions (e.g., Society of Women Engineers, American Women in Science, and Association of Women in Mathematics). These organizations all offer a wide range of support for members including professional networking, career mentorship, scholarships, etc.

Several well-established organizations supporting blacks in STEMM fields trace their histories to the 1970s (e.g., National Organization for the Professional Advancement of Black Chemists and Chemical Engineers, Organization of Black Aerospace Professionals, National Society of Black Engineers, and National Society of Black Physicists). All of these organizations offer a sophisticated and extensive range of services from professional networking to leadership development to public policy advocacy and scholarships for promising students.

Similar well-established organizations exist to support other minority communities. SACNAS and The Society for Professional Engineers (SHPE) provide extensive support for Hispanic and Latinx professionals in STEM. The American Indian Science and Engineering Society supports American Indians, and the Society of Asian Scientists and Engineers offers similar supports for professionals of Asian heritage.

oSTEM (Out in Science, Technology, Engineering, and Mathematics) was one of the very few organizations that we found supporting the LGBTQ + community in STEMM. With student and professional chapters in cities around the world oSTEM offers a range of support services for its members including annual and regional conferences, mentorship and leadership programs, awards, and online links to other affinity groups and crisis-management resources.

All of the above organizations take organizational forms that mirror the well-established professional associations, with membership dues, boards of directors, annual meetings, themebased committees, action plans, etc. More recently, several newer

${ }^{2}$ The authors would be delighted to add more resources to this website. Please email ofcd@wesleyan.edu if you know of an organization that should be added. organizations have emerged with more fluid membership forms. These tend to have much more sophisticated websites, emphasize social network platforms as a way of connecting, and are more likely to be intersectional in their identity. Examples of these kinds of groups include Latinas in STEM, Blacks in Technology, and Out to Innovate.

Additionally, Twitter has become an increasingly common way for underrepresented scholars to organize among themselves. Many of these efforts have grown from Twitter-based conversations to fullfledged identity groups that hold conferences and offer a range of other professional opportunities for members. We did not perform a review of the Twitter space for this article, focusing instead on mainline professional associations, but we would like to offer a few examples here to illustrate how quickly these types of organizations are growing: Black Botanist Week, Black in Microbiology, Black in Astro, and Black in SciComm.

In sum, most of the pro-diversity professional support in STEMM fields that we found was located not in the mainline professional associations but rather in affinity-based groups that have been forming organizations that have provided mutual support, professional development, and advocacy for decades. Furthermore, new organizations are forming regularly to find innovative ways to support increased and increasing diversity in STEMM.

\section{CONCLUSION AND RECOMMENDATIONS}

Our review of STEMM professional associations' resources related to diversity has revealed that while all of them recognize their legacy of racism that has created the significant under-representation of women and people of color in their fields (as evidenced by the universal presence of statements in support of Black Lives Matter), they could be doing much more to help support diverse professionals in their fields.

Specialized affinity-based organizations have been formed to address the weaknesses present in the mainline associations. These affinity organizations are often modeled on the mainline professional associations and offer a range of traditional support for their members, such as annual conferences, networking, mentoring, and funding. A few also provide a platform to showcase the talent of their members. The newest groups take a less traditional organizational form and are more sophisticated in their use of technology, leveraging social media platforms to facilitate networking and career development.

Given our findings, we have three main recommendations for the mainline professional associations as they seek to realize the diversity goals articulated in their 2020 diversity statements.

1) Develop robust relationships with affinity groups already associated with your discipline. Of all the associations we reviewed, only the American Institute of Biological Sciences contained a link to a related affinity group (SACNAS) on its landing page (as a "featured member"). ${ }^{3}$ Many of these

${ }^{3}$ The American Chemical Society (ACS) and the National Association for the Professional Advancement of Black Chemists and Chemical Engineers (NOBCChE) have had a long standing partnership, but it is not highlighted on ACS's web page. 
affinity-based groups have decades of experience related to recruiting, retaining, and promoting professionals from under-represented backgrounds. The mainline organizations should take advantage of their experience and expertise and form mutually beneficial partnerships:

- Co-sponsor events and conferences

- Have designated slots on Boards of Trustees for affinitygroup leadership, to ensure that their perspectives and experience are included in decision making

- Co-promote recruitment and teaching resources

- The mainline associations can use their greater financial resources to support activities of the affinity groups

- The affinity groups can use their greater access to students and professionals from under-represented groups to help the mainline associations recruit new members and access talented leadership.

2) Do more to showcase diverse members. Professional associations are all seeking to disrupt the stereotype that their fields are dominated by white men. However, if they have no pictures of any people on their websites and the few pictures that they do have do not show women or people of color, they are perpetuating that stereotype. Furthermore, to reduce macro and microaggressions directed toward professionals from non-traditional backgrounds, professional associations need to publicize and normalize the fact that people of all backgrounds are making important contributions to STEMM. Because contributions of underrepresented groups to STEMM fields have been ignored and discounted for centuries, professional associations must make extra efforts to publicize their talent and discoveries now.

3) Diversify association leadership and staff. Only a very few STEMM professional associations had visibly diverse boards of directors and even fewer had presidents who are women or people of color. As the previous sections make clear, numerous exceptionally talented professionals from diverse backgrounds exist in every single STEMM field. If professional associations are going to thrive in the 21st Century, they must diversify their leadership and incorporate the perspectives of a broader range of talent into their decision-making. As indicated in the first recommendation, one

\section{REFERENCES}

Botella, C., Rueda, S., López-Iñesta, E., and Marzal, P. (2019). Gender Diversity in STEM Disciplines: A Multiple Factor Problem. Entropy (Basel) 21 (1), 30. doi:10.3390/e21010030

Briggs, C. (2017). The Policy of Stem Diversity: Diversifying Stem Programs in Higher Education. J. Stem Edu. 17 (4), 5-7.

Drury, B. J., Siy, J. O., and Cheryan, S. (2011). When Do Female Role Models Benefit Women? The Importance of Differentiating Recruitment from Retention in Stem. Psychol. Inq. 22 (4), 265-269. doi:10.1080/ 1047840x.2011.620935

Jones, J., Williams, A., Whitaker, S., Yingling, S., Inkelas, K., and Gates, J. (2018). Call to Action: Data, Diversity, and Stem Education. Change Mag. Higher Learn. 50 (2), 40-47. doi:10.1080/00091383.2018.1483176

Steinke, J., Applegate, B., Penny, J. R., and Merlino, S. (2021). Effects of Diverse Stem Role Model Videos in Promoting Adolescents' Identification. Int. J. Sci. Math. Edu. 2, 1-22. doi:10.1007/s10763-021$10168-\mathrm{z}$ easy way to do this would be to create partnerships with affinity groups that are active in the field and have those groups send a representative to serve on the mainline association's Board of Trustees.

In sum, 1 year after their 2020 statements in support of diversity amidst the Black Lives Movement, many STEMM professional associations are not living up to their potential. There are thousands of women and people of color pursuing meaningful careers and making important contributions to all STEMM fields, but many are not yet well supported by their mainline professional associations. Some of the smaller, identity-based professional groups are filling in the gaps left by the mainline groups, but their efforts remain marginal to the activities of the field. The STEMM professional associations are very well positioned to use their institutional resources-financial, professional, and technical-to transform their professions and the broader society, making it more inclusive, dynamic, creative, and effective. Fundamental change will take a long time, but the small low-cost changes that we recommend above will go a very long way to promoting inclusion in STEMM.

\section{DATA AVAILABILITY STATEMENT}

The original contributions presented in the study are included in the article/Supplementary Material, further inquiries can be directed to the corresponding author.

\section{AUTHOR CONTRIBUTIONS}

All authors contributed equally to this article and take full responsibility for its contents. $\mathrm{MAH}$ was responsible for most of the writing up of the analysis. TJ was primarily responsible for website gathering and analysis. BS was primarily responsible for analysis, technical expertise, and organization. AW was responsible for most of the literature review and policy recommendations. All authors were responsible for final editing.

Yonas, A., Sleeth, M., and Cotner, S. (2020). In a "Scientist Spotlight" Intervention, Diverse Student Identities Matter. J. Microbiol. Biol. Educ. 21 (1), 25. doi:10.1128/jmbe.v21i1.2013

Conflict of Interest: The authors declare that the research was conducted in the absence of any commercial or financial relationships that could be construed as a potential conflict of interest.

Publisher's Note: All claims expressed in this article are solely those of the authors and do not necessarily represent those of their affiliated organizations, or those of the publisher, the editors and the reviewers. Any product that may be evaluated in this article, or claim that may be made by its manufacturer, is not guaranteed or endorsed by the publisher.

Copyright (c) 2021 Haddad, Jenkins, Solivan and Williams. This is an open-access article distributed under the terms of the Creative Commons Attribution License (CC BY). The use, distribution or reproduction in other forums is permitted, provided the original author(s) and the copyright owner(s) are credited and that the original publication in this journal is cited, in accordance with accepted academic practice. No use, distribution or reproduction is permitted which does not comply with these terms. 


\section{APPENDIX:}

List of Mainline Professional Associations We Surveyed. American Association for the Advancement of Science (AAAS) American Astronomical Society American Chemical Society (ACS)

American Geophysical Union

American Geosciences Institute (AGI)

American Institute of Biological Sciences (AIBS)

American Medical Association American Physical Society (APS) American Psychological Association American Society for Cell Biology (ASCB)
American Society for Civil Engineers (ASCE)

American Society for Mechanical Engineers (ASME)

American Society for Microbiology (ASM)

American Statistical Association

Animal Behavior Society (ABS)

Association for Computing Machinery (ACM)

Association of Environmental and Engineering Geologists (AEG)

Biomedical Engineer Society

Federation of American Societies for Experimental Biology (FASEB)

IEEE Computer Society

Mathematical Association of America (MAA)

Society for Neuroscience 